\title{
Basilar Artery
}

National Cancer Institute

\section{Source}

National Cancer Institute. Basilar Artery. NCI Thesaurus. Code C12676.

An artery formed by the union of the two vertebral arteries at the posterior border of the pons then diverges at the anterior border forming the two superior and two posterior cerebral arteries. 